\title{
Evaluation of Diabetic Rats Behavior after Treatment by Artemisia herba-alba Relative to Insulin
}

\section{Yahia M. Bushara ${ }^{1,2}$, Abdelhay Mohammed Ali ${ }^{3,4}$, Mohammed A. Ali Omer ${ }^{2,5 *}$, John Gergis Gouda ${ }^{1}$, Paul F. Seke Tet ${ }^{2}$, Mohamed F. Mohamed ${ }^{2}$}

\author{
${ }^{1}$ Department of Anatomy, Faculty of Medicine, Al-Neelain University, Khartoum, Sudan \\ ${ }^{2}$ Department of Basic Health Sciences \& Radiologic Technology, College of Applied Medical Science, Qassim University, \\ Buraidah, KSA \\ ${ }^{3}$ Department of Anatomy, Faculty of Veterinary Medicine, University of Khartoum, Khartoum, Sudan \\ ${ }^{4}$ Department of Anatomy, College of Veterinary Medicine, King Faisal University, Hofuf, KSA \\ ${ }^{5}$ Department of Radiation Therapy, College of Medical Radiologic Science, Sudan University of Science \& Technology, \\ Khartoum, Sudan \\ Email:busharayahia@yahoo.com, abdehaym@hotmail.com, ^alkajam@gmail.com,paul.seke@gmail.com, \\ farahnamohammed@hotmail.com
}

How to cite this paper: Bushara, Y.M., Ali, A.M., Omer, M.A.A., Gouda, J.G., Tet, P.F.S. and Mohamed, M.F. (2017) Evaluation of Diabetic Rats Behavior after Treatment by Artemisia herba-alba Relative to Insulin. Journal of Diabetes Mellitus, 7, 1-11. https://doi.org/10.4236/jdm.2017.71001

Received: November 24, 2016

Accepted: January 9, 2017

Published: January 12, 2017

Copyright $\odot 2017$ by authors and Scientific Research Publishing Inc. This work is licensed under the Creative Commons Attribution International License (CC BY 4.0).

http://creativecommons.org/licenses/by/4.0/ (c) (i) Open Access

\begin{abstract}
The aim of the study was to evaluate the behavioral signs of diabetic rats after treatment by Artemisia herba-alba (AHA) and insulin. Method: Based on the induction of diabetes in wistar rats by intraperitoneal (I/P) injection of 60 $\mathrm{mg} / \mathrm{kg}$ streptozotocin (STZ), then treated by AHA as $20 \mathrm{mg}(\mathrm{I} / \mathrm{P})$ and insulin subcutaneously (S/C). The samples of rats were: 1) Diabetic control, 2) Injected with insulin, 3) Injected with AHA, 4) Non diabetic rats, which were fostered for 21 day; then weighted and the behavioral tests were conducted. Results: The board hole tests (BHT) showed that: the induced diabetes reduced the cognition of the rats in view of Latency of the First Head Dipping (LFHD) in seconds, number of head dipping (NHD) and duration of head dipping (DHD) by 49.3\%, while it's improved in AHA and insulin treated rats by $52 \%$ and $69 \%$ in average respectively. The exploratory activity reduced in diabetic rats by $36 \%$, while AHA and Insulin treated rats increased by $53 \%$ and $72 \%$ respectively. The rearing test showed an increase of anxiety among diabetic in form of duration of rearing, number of rearing and time spend in center by $51.7 \%$ in average respectively, while the anxiety reduced after treatment by AHA and insulin by $39 \%$ and $47.3 \%$ in average respectively. Also the diabetes increased the depression state by $106 \%$, while the treatment by AHA and insulin reduced the depression state by $77 \%$ and $88 \%$ respectively. And VPT showed that: motor impairment occurred in diabetic cases and improved after AHA and insulin treatment.
\end{abstract}




\section{Keywords}

Diabetes, Artemisia, Behavioral, Herbal, Treatment, Insulin

\section{Introduction}

Diabetes mellitus is a serious metabolic disorder in humans. It is a chronic endemic endocrine disease, resulting from defective insulin secretion or resistance to insulin action, or both [1]. The disease is characterized by hyperglycemia leading increased fatigability, polydipsia, polyuria, polyphagia, weight fluctuation, blurry vision, irritability, infections, poor wound healing, microangiopathy, and it may ends with serious complications. The main two types of the diabetes mellitus were type 1 diabetes (insulin-dependent diabetes mellitus) which is characterized by an autoimmune-mediated destruction of pancreatic $\beta$-cells, leading to insulin deficiency and without treatment the case turns to ketoacidosis. Autoantibodies against insulin can be detected in $85 \%-90 \%$ of patients at the time of diagnosis [2]. The incidence of type 1 diabetes is 8 - 20 per 100,000 patientyears in children up to 18 years of aged. After the age of 20 , the incidence is lower, with little further effect of aged. Type 1 represents $15 \%-20 \%$ of all diabetic patients [3]. Type 2 diabetes is characterized by insulin resistance and relative insulin deficiency [4]. Treatment aims to reduce insulin resistance (for example, with diet, exercise or drug therapy) and to increase endogenous insulin secretion. The incidence of type 2 diabetes (previously defined as non-insulin-dependent diabetes mellitus) is estimated to be about 5 per 100,000 patient-years in subjects up to 29 years of age, increasing sharply up to 500 per 100,000 patient/years in subjects over 70 [5]. The prevalence of diabetes ranges from about $2 \%$ in subjects aged $20-44$ years to $18 \%$ in subjects aged $65-74$ years, and over $20 \%$ in subjects of 85 and older [6]. Both forms of diabetes are associated with long-term complications that affect the eyes, kidneys, heart, blood vessels and nerves [7]. The development of these complications is dependent on the duration of diabetes and the quality of metabolic control [8] and can be only partially prevented by intensive insulin treatment. Both types of diabetes affect nervous system and showed neuropsychological changes [9]. Type 1 diabetic patients show different ranges of cognitive changes and impairments in learning and memory, problem solving, and mental and motor speed [10] [11]. As well type 2 diabetic patients showed chronic hyperglycemia, dyslipidemia peripheral neuropathy which were prone to moderate cognitive impairment particularly in tasks involving verbal memory or complex information processing, while attention processes, motor reaction time and short-term memory are relatively unaffected [9]. In addition, vascular dementias, Alzheimer's disease [12], cortical and subcortical atrophy [13], and white-matter hyperintensities [14] have association with diabetic disease. The efforts to manage such drastic endemic disease have been carried out by many scholars, and the major components of the treatment are: Diet (combined with exercise if possible), Oral hypoglycemic therapy and 
insulin treatment [15], and the Appropriate medication targeting glycemic control, hypertension, and lipid management for reducing morbidity and mortality, and improving long-term quality of life for patients diagnosed with type 2 diabetes mellitus (T2DM) [16], in addition to herbal medication efforts as gurmar leaf (Gymnema sylvestre), bitter gourd fruit (Momordica charantia), and fenugreek seeds (Trigonella foenumgraecum) may be among the best in terms of efficacy and safety [17] up on which $65 \%-80 \%$ of world population depends on for their medication [18]. As the attempt has been continuing to beer out the efficiency of herbal medication, the trend of the current work is to evaluate the behavioral signs of diabetic rats after treatment by Artemisia herba-alba (AHA) relative to Insulin. AHA or (Shih) exists in North Africa, the Mediterranean basin, parts of Asia and Middle East extending into northwestern Himalayas and in Spain [19]. Its extraction is popularly used in treatment of diabetes mellitus, due it is hypoglycemic activity [20], administration of $85 \mathrm{mg} / \mathrm{kg}$ body weight of AHA might be useful in preventing hyperglycemia and reduces blood glucose in both normoglycemic and hyperglycemic rabbits [21], and its phenolic constituent showed significant higher antioxidant effect, which is closer to that of the synthetic antioxidants [22]. The full mode of action of the AHA in lowering blood glucose is under investigation, although some scientists propose, that the herbal drugs can show their effects by acting as; $\alpha$-Glucisidase or $\alpha$-Amylase Inhibitor [23] or Increases Insulin Secretion [24] [25] or stimulate $\beta$-cell regeneration by proliferation of its precursor or cells in the pancreatic duct [26], recently the AHA has been found to act as anti-diabetic derivative, by increasing insulin secretion through regenerating new $\beta$-cells mass in STZ diabetic induced rats [27], so relieving of diabetes in rats will improve the symptoms accompanied the disease including the behavioral ones.

\section{Methodology}

\subsection{Tools \& Equipments}

- The Drugs

1) Insulin: long-acting insulin, ultralentehumulin $\mathrm{U}$ (lily), $0.5 \mathrm{ml} / \mathrm{rat}, \mathrm{S} / \mathrm{C}$ (subcutaneous).

2) Herbs: AretemisiaHerba Alba was purchased from Khartoum medical herbs market. It was finely grinded, packed and subjected to $70 \%$ ethyl alcohol extraction. The extract was left to dry and dissolved as four grams of the herb in $24 \mathrm{ml}$ of 6\% DSMO (dimethylsulphoxide-dissolvent, used as vehicle transport to other material without affecting the tissue [28]) +376 distilled water $=400 \mathrm{ml}$ of extract solution, each $\mathrm{ml}=10 \mathrm{mg}$ of dissolved herb to be administered as $2 \mathrm{ml}$ (20 mg)/Rat, I/P (intraperitoneal).

3) Glucometer: (i care TD-4279) Blood Glucose Monitoring System.

4) Streptozotocin (STZ): (STZ, has a chemical formula of $\mathrm{C}_{8} \mathrm{H}_{15} \mathrm{~N}_{3} \mathrm{O}_{7}, 265$ $\mathrm{g} / \mathrm{mol}$ which implies nitrosourea moiety with a methyl group attached to one end and a glucose molecule at the other end. STZ was prepared by adding 750 $\mathrm{mg}$ of STZ to 1.47 grams of sodium citrate $(100 \mathrm{mM})$ to $50 \mathrm{ml}$ of $9 \%$ sodium 
chloride, the solution was injected $\mathrm{I} / \mathrm{P}, 60 \mathrm{mg} / \mathrm{kg}$.

- The Hole Board Test apparatus: (The hole board test was developed by Boissier and Simon, [29]. The arena comprised of a square Plexiglass box measuring $80 \mathrm{~cm} \times 80 \mathrm{~cm}$ with equally spaced 16 holes in the floor $6 \mathrm{~cm}$ in diameter)

- Vertical pole Test apparatus: is cloth-tape covered vertical pole of an iron fixed on a piece of concrete. It is $150 \mathrm{~cm}$ long and $3 \mathrm{~cm}$ in diameter.

- Wistar Rats: rats of same ages, and sexes (males) were brought from the animal house of the faculty of medicine.

\subsection{Methodology}

Sixty four (64) Wister rats of same ages and sexes were brought from the animal house of the faculty of medicine. The rats were housed in a well prepared research room, encaged in sixteen cages, four rats per each, and left for two week before the experiment start to be adapted for the new housing conditions. Then the rats were labeled and weighed which were in range of 328.74 grams as average.

Four days later the effect of STZ (60 mg/kg I/P) was examined and showed an increase of blood glucose from $70 \mathrm{mg} / \mathrm{dl}$ to $320 \mathrm{mg} / \mathrm{dl}$ after 5 day flowing injection. Two weeks later the blood glucose of all rats was estimated; which was in the range of $70-110 \mathrm{mg} / \mathrm{dl}$, then forty (40) rats were randomly selected and injected with STZ (60 mg/kg I/P). And after five days their blood glucose raised to more than $320 \mathrm{mg} / \mathrm{dl}$ (diabetic) as tested, from which twenty four (24) rats were randomly selected and divided into three (3) groups each implies eight rats and nominated as:

Group A: as diabetic treated with insulin, with S/C dose of $0.5 \mathrm{ml}$ insulin.

Group B: as diabetic treated with AHA with (I/P) dose of $20 \mathrm{mg} / \mathrm{Rat}$.

Group C: diabetic, injected with $2 \mathrm{ml}$ of distilled water (I/P) daily (diabetic control).

The rest of the sample (24 normal rats) a group of eight (8) rats have been selected randomly and nominated as:

Group D: non-diabetic, injected with $2 \mathrm{ml}$ of distilled water (I/P) daily (normal control).

The rats of all groups were weighed (Group $\mathrm{A}=301.88 \pm 118.9$ Group $\mathrm{B}=$ $336.57 \pm 42.9$ Group $C=355.63 \pm 68.1$ Group $\mathrm{D}=320.88 \pm 647$ ) and each group kept in a separate cage for 21 days.

During these 21 days, the experimental study has been carried out as general health observation; which showed no mortality among the sample. On twenty second $\left(22^{\text {nd }}\right)$ day; the rats were weighed in grams (Group $A=344.13 \pm 53.4$, Group $B=340.57 \pm 40.0$, Group $C=342.13 \pm 56.1$ and Group $D=325.13 \pm$ 66.1) and their blood glucose was estimated (Group $A=93 \mathrm{mg} / \mathrm{dl}$, Group $B=$ $100 \mathrm{mg} / \mathrm{dl}$, Group $C=355 \mathrm{mg} / \mathrm{dl}$ and Group $D=80 \mathrm{mg} / \mathrm{dl}$ ) then all of the rats subjected to behavioral studies.

Behavioral Test

1) Vertical Pole Test (VPT): 
VPT has been used to assess basal ganglia-related motor movement disorders in rodents [30] [31]. The rats are placed head-up on a cloth-tape covered vertical pole (150 cm long, $3 \mathrm{~cm}$ in diameter); when placed on the pole, animals orient themselves downward and descend the length of the pole. Animals with deficits in motor coordination and balance will fall off the pole [32] [33]. Animal time to orient downward ( $\mathrm{t}$-turn), reflect of cognitive abilities and the total time the animals stays on the pole (t-total), reflect of motor coordination ability [34] are determined from video recordings for a maximum of 180 seconds.

\section{2) Hole Board Test (HBT):}

The procedure of this experiment can be modified depending on the behavior being measured. Rats were individually subjected to the test. During the test, each rat was placed at the center of the platform and the activity in the arena was video recorded for a $5 \mathrm{~min}$ period. The video recordings were scored and the following exploratory behavior parameters were measured: the Latency of First Head Dipping (LFHD), Number and Total Duration of Episodes of Head Dipping through the holes ("nose-poking", which represent a possible way to escape from the aversive environment and therefore reflect the escape response of the animal, which is a normal cognitive ability [35], the total distance travelled on the arena (ambulation score) rearing episodes, and the latency to the first grooming were recorded. The apparatus was cleaned with $95 \%$ alcohol after every trial.

1) Cognition: Estimated by counting the Latency of Time in seconds that taken by every rat for the first head dipping in a hole, by counting the head dipping numbers and by counting the head dipping duration in seconds.

2) Exploratory activity: done by measuring the distance traveled by a rat in the arena of the board $/ \mathrm{cm}$.

3) Anxiety: done by counting the numbers of rearing against wall of the box of the board, duration of rearing/s and the time spent in centre of the board/s by each rat.

4) Depression: estimated by the latency of time in seconds spent by a rat before commencing the first grooming episode.

\section{Results}

The following are the results of Rats behavior after induction of diabetes and treatment with AHA and Insulin, with specific attention to Latency of First Head Dipping per seconds (LFHD/s), Number of Head Dipping (NHD) and the Head Dipping Duration per seconds (HDD/s) for the control group, diabetic group, group treated with AHA and group treated with Insulin.

\section{Discussion}

Based on the accumulated knowledge that: diabetes used to change the host behavior, which can be improved by the anti-diabetic medication, it is found that treatment of diabetic rats with AHA and insulin improve some behavioral signs compared to the non-treated ones out of behavioral tests (HBT and VPT). 
In the following study; the board hole tests (BHT) showed that: the induced diabetes reduced the cognition of the rats in parameters of Latency of the First Head Dipping (LFHD) in seconds, number of head dipping (NHD) and duration of head dipping (DHD) from (100\%) $35 \mathrm{~s}$ to (60\%) $22.4 \mathrm{~s}$, from (100\%) 9.6 times to (58.3\%) 5.6 times, and from (100\%) $20 \mathrm{~s}$ to (50\%) $10 \mathrm{~s}$ respectively; while its improved in AHA and insulin treated rats to (92.6\%) $32.4 \mathrm{~s}$, (108.3\%) 10.4 times, (123\%) $24.6 \mathrm{~s}$, and ((114.3\%) 40 s., (133.3\%) 12.8 times, and (128\%) 25.6 s)) respectively as shown in Figure 1, same results have been highlighted by Rogacki et al., [36] in which they stated that: the healthy animals take longer time to begin the first head dipping. The exploratory activity was reduced in diabetic non treated rats from (100\%) $1440 \mathrm{~cm}$ to (63.9\%) $920 \mathrm{~cm}$ while AHA and Insulin treated rats increased to (88.9\%) $1280 \mathrm{~cm}$, and (108.3\%) $1560 \mathrm{~cm}$ respectively as shown in Figure 2, in the same realm Deacon et al., [37] found the decrement of exploratory activity which indicates the impairment in motor

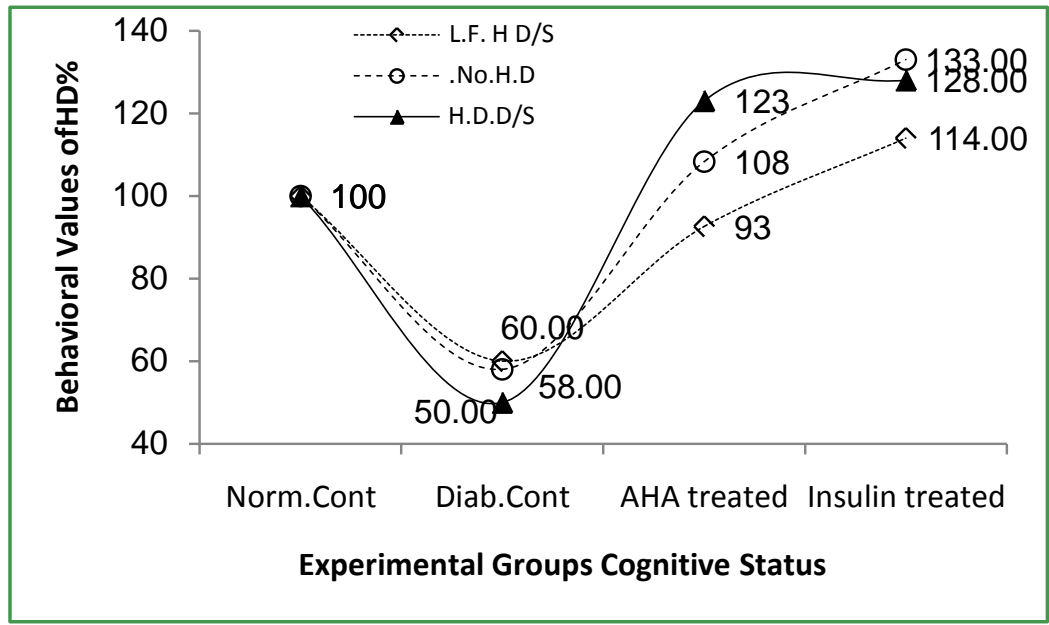

Figure 1. Shows latency of first head-dipping/seconds, head dipping number and head dipping duration/seconds after induction of diabetes by STZ relative to treatment with AHA, and insulin $(100 \%=35$ s, 9.6 times \& 20 s respectively).

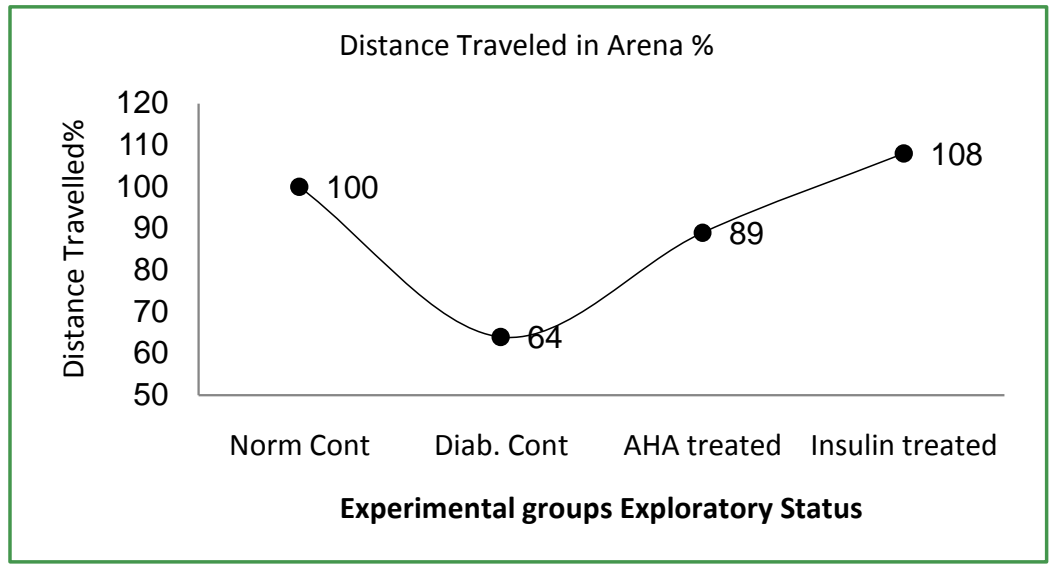

Figure 2. Shows distance traveled on the arena after induction of diabetes by STZ and the relative distance traveled on the arena after treatment with AHA, and insulin $(100 \%=1440 \mathrm{~cm})$. 
function. Also rearing test showed an increase of anxiety among diabetic in form of duration of rearing, number of rearing and time spend in center as from (100\%) $12 \mathrm{~s}$ to $(33.3 \%) 4 \mathrm{~s}$, from (100\%) 4 times to (50\%) 2 times, and from (100\%) $370 \mathrm{~s}$ to $(62.2 \%) 230 \mathrm{~s}$ respectively. while these parameters (duration of rearing, number of rearing and time spend in center) reduced in AHA and insulin to $(58.3 \%) 7 \mathrm{~s}$ and (66.7\%) $8 \mathrm{~s}$, (90\%) 3.6 times and (120\%) 4.8 times, and (113.5\%) $420 \mathrm{~s}$ and (100\%) $370 \mathrm{~s}$ respectively as shown in Figure 3, such result has been mentioned in the introduction section by Moriera et al., [38] and Brown et al., [35]. While the BHT reveal the elevated depression state of diabetic rats in form of increasing the latency of first grooming episode (LFGE) from (205.9\%) $350 \mathrm{~s}$ to (100\%) $170 \mathrm{~s}$; and the LFGE reduced to (76.5\%) $130 \mathrm{~s}$ and (88.2\%) $150 \mathrm{~s}$ in AHA and insulin respectively as shown in Figure 4, same result has been stated by Pires et al., [39] in the introduction section. The VPT revealed

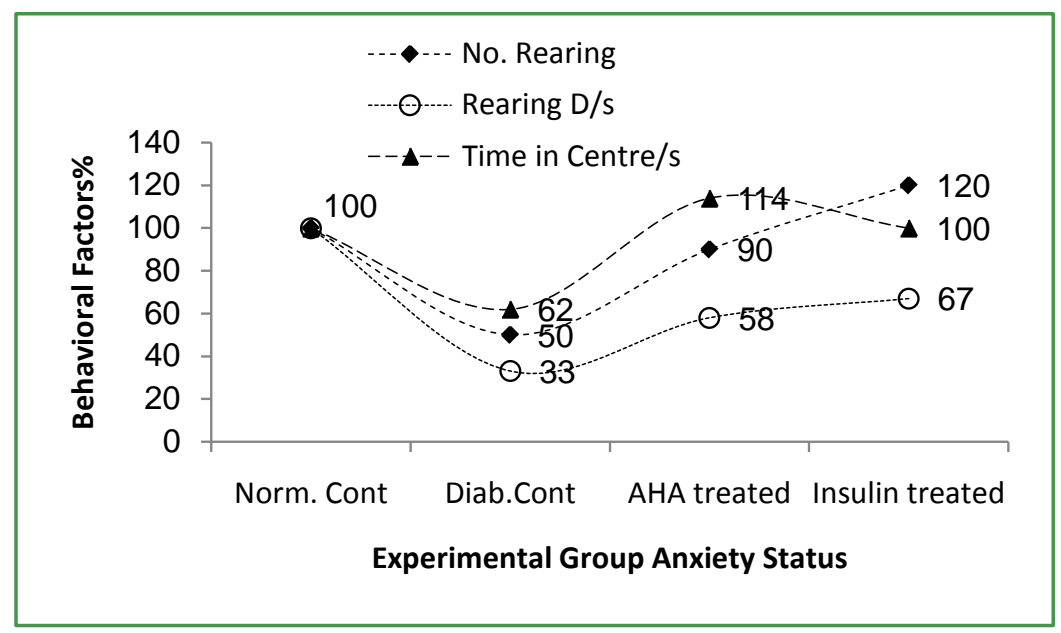

Figure 3. Shows rearing episode number, rearing episode duration \& time spent in the arena center after induction of diabetes by STZ relative to the treatment with AHA, and insulin ( $100 \%=4$ times, $12 \mathrm{~s} \& 370$ s respectively).

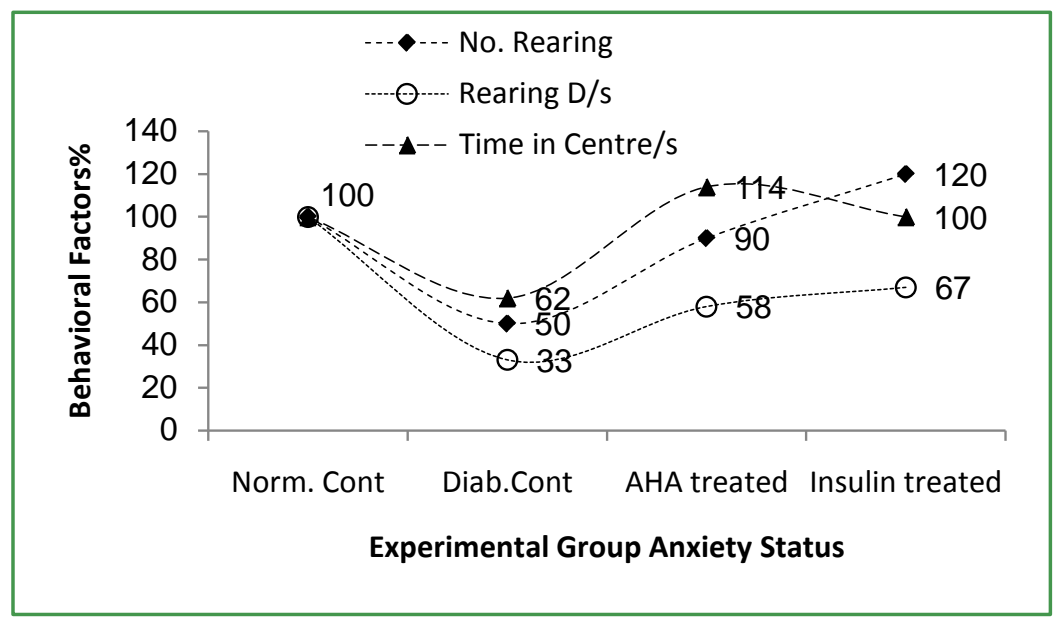

Figure 4. Shows latency of first grooming episode/second, after induction of diabetes by STZ and the relative grooming first latency after treatment with AHA, and insulin $(100 \%=170 \mathrm{~s})$. 
the motor impairment in diabetic rats in form of time taken on pole (TTP) and increase time to begin the first turn (TTFT) as decrement and increment by (39.1\%) $36 \mathrm{~s}$ and (216.7\%) $13 \mathrm{~s}$ relative to normal (100\%) $92 \mathrm{~s}$ and (100\%) $6 \mathrm{~s}$ respectively, while TTP and TTFT improved by increment and decrement as (82.6\%) $76 \mathrm{~s}$ and (100\%) $92 \mathrm{~s}$ and (50\%) $3 \mathrm{~s}$ and (100\%) $6 \mathrm{~s}$ respectively as shown in Figure 5 and Figure 6, ascertaining this fact the result obtained by Simmons et al., [32] and Tanriover et al., [32] [33]. The general improvement of the behavioral signs among diabetic rats after injection of AHA was ascribed to the new generation of $\beta$-cells in the islets of Langerhans of the pancreas as confirmed in histological section done by Yahia et al. [27].

\section{Conclusion}

The utilization of AHA as traditionally being used as antidiabetes by some universe population as well as classical herbal medicine for gastric disturbance, it showed a considerable obvious improvement in behavioral sign among diabetic rats; which encourage and open the trends for scholars and pharmacologists to

(a) Healthy animal

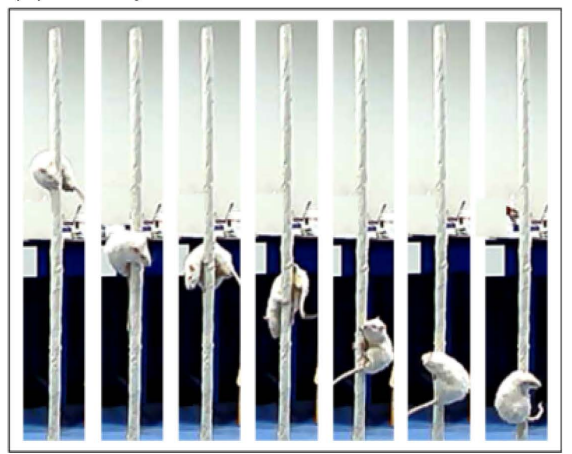

(b) Diabetic animal

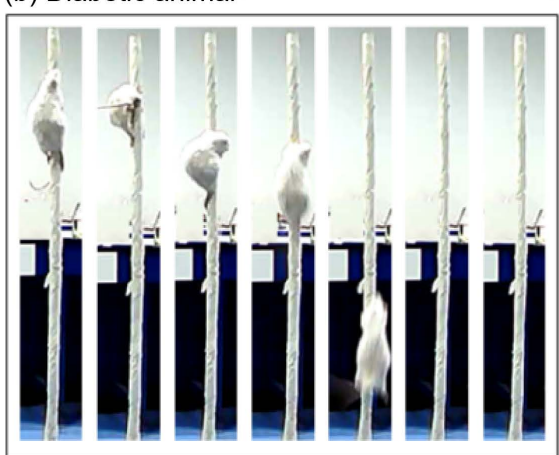

Figure 5. shows total time on the pole and the latency of the first turn in the vertical pole test (a) the healthy non diabetic rat; (b) STZ diabetic induced non treated rat.

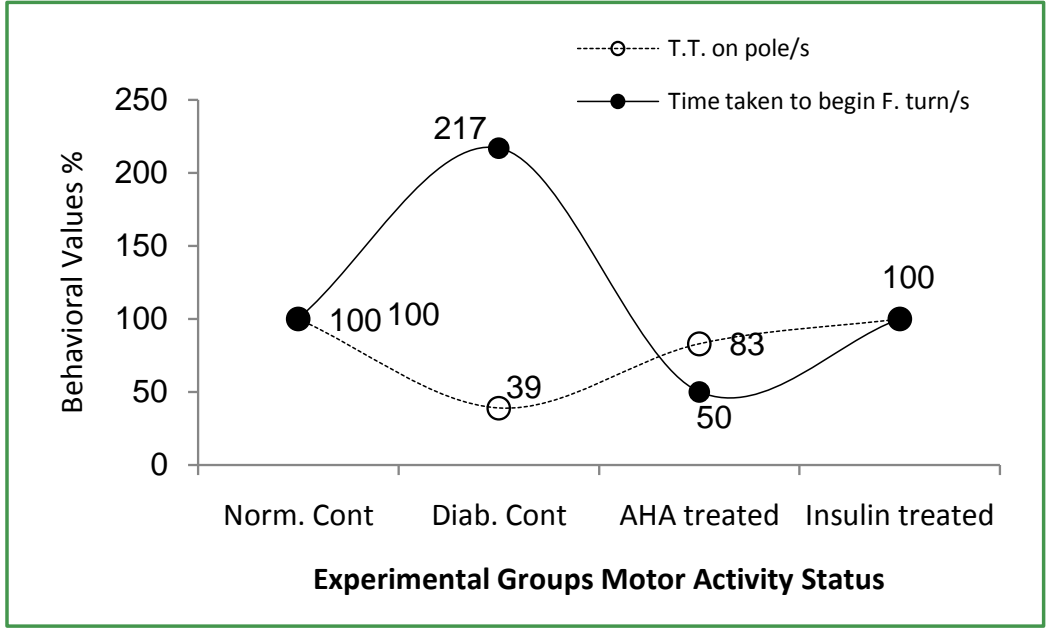

Figure 6. Motor impairment in vertical pole test: Shows total time taken on the pole and time taken to begin the first turn/seconds after induction of diabetes by STZ and the relative treatment with AHA and insulin (100\% = 92 S, 6 S). 
search deeply to emphasize it is benefit and further the commercialization issues of AHA.

\section{References}

[1] World Health Organization (1997) Expert Committee on the Diagnosis and Classification of Diabetes Mellitus: Report on the Diagnosis and Classification of Diabetes Mellitus. Diabetes Care, 20, 1183-1197. https://doi.org/10.2337/diacare.20.7.1183

[2] Knip, M., Veijola, R., Virtanen, S.M., Hyoty, H., Vaarala, O. and Akerblom, H.K. (2005) Environmental Triggers and Determinants of Type 1 Diabetes. Diabetes, 54, S125-S136. https://doi.org/10.2337/diabetes.54.suppl_2.S125

[3] Urger, H. and Foster, W. (1998) Diabetes Mellitus. In: Wilson, J.D., Foster, D.W., Kronenserg, M. and Larson, R., Eds., Williams's Text Book of Endocrinology, WB Saunders, Philadelphia, 973-1060.

[4] Kameswara Rao, B., Kesavulu, M.M. and Apparao, C. (2003) Evaluation of Hypoglycemic Effect of Momordica cymbalaria Fruit in Alloxan-Diabetic Rats. Fitoterapia, 74, 7-13. https://doi.org/10.1016/S0367-326X(02)00297-6

[5] Melton, L.J., Palumbo, P.J. and Chu, C.P. (1983) Incidence of Diabetes Mellitus by Clinical Type. Diabetes Care, 6, 75-86. https://doi.org/10.2337/diacare.6.1.75

[6] Ott, A., Stolk, R.P., Hofman, A. and Van Harskamp, F. (1996) Association of Diabetes Mellitus and Dementia: The Rotterdam Study. Diabetologia, 39, 1392-1397. https://doi.org/10.1007/s001250050588

[7] Omer, M.A.A., Eljack, A.H., Gar-Alnabi, M.E.M., Mahmoud, M.Z., Elseid, M. and Edam, G.A. (2014) Ultrasonographic Characteristics of Diabetes Impacts in Kidneys' Morphology. Open Journal of Radiology, 4, 301-308. https://doi.org/10.4236/ojrad.2014.44039

[8] Pirart, J. (1978) Diabetes Mellitus and Its Degenerative Complications: A Prospective Study of 4,400 Patients Observed between 1947 and 1973 (Pt 1). Diabetes Care, 1, 168-188. https://doi.org/10.2337/diacare.1.4.252

[9] Strachan, M.W.J., et al. (1997) Is Type II Diabetes Associated with an Increased Risk of Cognitive Dysfunction? A Critical Review of Published Studies. Diabetes Care, 20, 438-445. https://doi.org/10.2337/diacare.20.3.438

[10] Biessels, G.J., Kappelle, A.C., Bravenboer, B., Erkelens, D.W. and Gispen, W.H. (1994) Cerebral Function in Diabetes Mellitus. Diabetologia, 37, 643-650. https://doi.org/10.1007/BF00417687

[11] Gold, A.E., Deary, I.J., Jones, R.W. and O'Hare, J.P. (1994) Severe Deterioration in Cognitive Function and Personality in Five Patients with Long-Standing Diabetes: A Complication of Diabetes or a Consequence of Treatment. Diabetic Medicine, 11, 499-505. https://doi.org/10.1111/j.1464-5491.1994.tb00314.x

[12] Stewart, R. and Liolitsa, D. (1999) Type 2 diabetes mellitus, cognitive impairment and dementia. Diabetic Medicine, 16, 93-112.

https://doi.org/10.1046/j.1464-5491.1999.00027.x

[13] Araki, Y., Nomura, M., Tanaka, H. and Yamamoto, H. (1994) MRI of the Brain in Diabetes Mellitus. Neuroradiology, 36, 101-103. https://doi.org/10.1007/BF00588069

[14] Ylikoski, H., Erkinjuntti, T., Raininko, R. and Sarna, S. (1995) White Matter Hyperintensities on MRI in the Neurologically Nondiseased Elderly. Analysis of Cohorts of Consecutive Subjects Aged 55 to 85 Years Living at Home. Journal of Stroke, 26, 1171-1177. https://doi.org/10.1161/01.STR.26.7.1171

[15] Alwan, A.A.S. (1994) Management of Diabetes Mellitus Standards of Care and 
Clinical Practice Guidelines. WHO Regional Office for the Eastern Mediterranean (WHO-EM/DIN6/E/G), Alexandria.

[16] Redmon, B., Caccamo, D., Flavin, P., Michels, R., O’Connor, P., Roberts, J., Smith, S. and Sperl-Hillen, J. (2014) Diagnosis and Management of Type 2 Diabetes Mellitus in Adults. 16th Edition, Institute for Clinical Systems Improvement.

[17] Marles, R.J. and Farnsworth, N.R. (1995) Antidiabetic Plants and Their Active Constituents. Phytomedicine: International Journal of Phytotherapy and Phytopharmacology, 2, 137-189. https://doi.org/10.1016/S0944-7113(11)80059-0

[18] Calixto, J.B. (2005) Twenty-Five Years of Research on Medicinal Plants in Latin America: A Personal View. Journal of Ethnopharmacology, 100, 131-134. https://doi.org/10.1016/j.jep.2005.06.004

[19] Salido, S., Valenzuela, L.R., Altarejos, J., Nogueras, M., Sanchez, A. and Cano, E. (2004) Composition and Infraspecific Variability of Artemisia herba-alba from Southern Spain. Biochemical Systematics and Ecology, 32, 265-277. https://doi.org/10.1016/j.bse.2003.09.002

[20] Jouad, H., Haloui, M., Rhiouani, H., El-Hilaly, J. and Eddouks, M. (2001) Ethnobotenical Survey of Medicinal Plants Used or the Treatment of Diabetes, Cardiac and Renal Diseases in the North Centre Region of Morocco (Fez-Boulemane). Journal of Ethnopharmacology, 77, 175-182. https://doi.org/10.1016/S0378-8741(01)00289-6

[21] Iriadam, M., Musa, D., Gümühan, H. and Baba, F. (2006) Effects of Two Turkish Medicinal Plants Artemisia herba-alba and Teucrium polium on Blood Glucose Levels and Other Biochemical Parameters in Rabbits. Journal of Cell and Molecular Biology, 5, 19-24.

[22] Khennouf, S., Nadjet, I., Abderrahmane, B., Daoud, H. and Lekhmici, A. (2010) Antioxidant and Antibacterial Activities of Extracts from Artemisia herba alba Asso. Leaves and Some Phenolic. Journal of Medicinal Plants Research, 4, 1273-1280.

[23] Kim, J.-S., Yang, J.F. and Kim, M.-J. (2011) Alpha Glucosidase Inhibitory Effect, Anti-Microbial Activity and UPLC Analysis of Rhusverniciflua under Various Extract Conditions. Journal of Medicinal Plants Research, 5, 778-783.

[24] Si, M.-M., Lou, J.-S., Zhou, C.-X., Shen, J.-N., Wu, H.-H., Yang, B., He, Q.-J. and Wu, H.-S. (2010) Insulin Releasing and Alpha-Glucosidase Inhibitory Activity of Ethyl Acetate Fraction of Acoruscalamus in Vitro and in Vivo. Journal of Ethnopharmacology, 128, 154-159. https://doi.org/10.1016/j.jep.2009.12.044

[25] Lee, W.K., Kao, S.-T., Liu, I.-M. and Cheng, J.-T. (2006) Increase of Insulin Secretion by Ginsenoside RH2 to Lower Plasma Glucose in Wistar Rats. Journal of Clinical and Experimental Pharmacology and Physiology, 33, 27-32. https://doi.org/10.1111/j.1440-1681.2006.04319.x

[26] Rosely, C.D., Melazzo, C., da Luz, S.C.A., Fiappi, A., Prestes, D., Da Silveira, A.F. and Cecim, M. (2004) Syzygiumcumini and the Regeneration of Insulin Positive Cells from the Pancreatic Duct. Brazilian Journal of Veterinary Research and Animal Sciences, 41, 236-239.

[27] Bushara, Y.M., Ali, A.M., Ali Omer, M.A., Babiker, A.Y. and Mohammed, M.F. (2016) Assessment of Morphological Changes in Pancreatic Islets of Diabetic Wistar Rats by Artemisia herba alba Treatment. International Journal of Current Research, 8, 31984-31989.

[28] Geiss, J. (2001) The Century of Space Science. Kluwer Academic, Boston, 20.

[29] Boissier, J.R. and Simon, P. (1965) Action of Caffeine on the Spontaneous Motility of the Mouse. Archives Internationales de Pharmacodynamie et de Thérapie, 158, 212-221. 
[30] Fernagut, P.O. and Chesselet, M.F. (2004) Alpha-Synuclein and Transgenic Mouse Models. Neurobiology of Disease, 17, 123-130. https://doi.org/10.1016/j.nbd.2004.07.001

[31] Zaitone, S.A., Abo-Elmatty, D.M. and Elshazly, S.M. (2012) Piracetam and Vinpocetine Ameliorate Rotenone-Induced Parkinsonism in Rats. Indian Journal of Pharmacology, 44, 774-779. https://doi.org/10.4103/0253-7613.103300

[32] Simmons, D.A., Mehta, R.A., Lauterbom, J.C., Gall, C.M. and Lynch, G. (2011) Brief Ampakine Treatments Slow the Progression of Huntington's Disease Phenotypes in R6/2 Mice. Neurobiology of Disease, 41, 436-444. https://doi.org/10.1016/j.nbd.2010.10.015

[33] Tanriover, G., Seval-Celik, Y., Ozsoy, O., Akkoyunlu, G., Savcioglu, F. and Hacioglu, G. (2010) The Effects of Docosahexaenoic Acid on Glial Derived Neurotrophic Factor and Neurturin in Bilateral Rat Model of Parkinson's Disease. Folia Histochemica et Cytobiologica, 48, 434-441. https://doi.org/10.2478/v10042-010-0047-6

[34] Yun, H.S., Park, M.S., Ji, E.S., Kim, T.W., Ko, I.G., Kim, H.B. and Kim, H. (2014) Treadmill Exercise Ameliorates Symptoms of Attention Deficit/Hyperactivity Disorder through Reducing Purkinje Cell Loss and Astrocytic Reaction in Spontaneous Hypertensive Rats. Journal of Exercise Rehabilitation, 10, 22-30. https://doi.org/10.12965/jer.140092

[35] Brown Gillian, R. and Nemes, C. (2008) The Exploratory Behaviour of Rats in the Hole-Board Apparatus: Is Head-Dipping a Valid Measure of Neophilia? Behavioural Processes, 78, 442-448. https://doi.org/10.1016/j.beproc.2008.02.019

[36] Rogacki, N., Lopez-Granch, M., Naimoli, V., Potestio, L., Stevens, R.J., Pichat, P., Bergis, O.E., Cohen, C., Vatry, G.B. and Griebel, G. (2011) The Neurokinin NK2 Antagonist, Saredutant, Ameliorates Stress-Induced Conditions without Impairing Cognition. Pharmacology Biochemistry \& Behavior, 98, 405-411. https://doi.org/10.1016/j.pbb.2010.11.017

[37] Deacon, R.M., Croucher, A. and Rawliins, J.N. (2002) Hippocampal Cytotoxic Lesion Effects on Species-Typical Behaviours in Mice. Behavioural Brain Research, 132, 203-213. https://doi.org/10.1016/S0166-4328(01)00401-6

[38] Moriera, E.G., Vassilieff, I. and Vassilieff, V.S. (2001) Developmental Lead Exposure: Behavioral Alterations in the Short and Long Term. Neurotoxicology and Teratology, 23, 489-495. https://doi.org/10.1016/S0892-0362(01)00159-3

[39] Pires, G.N., Alvarenga, T.A., Maia, L.O., Mazaro-Costa, R., Tufik, S. and Andersen, M.L. (2012) Inhibition of Self-Grooming Induced by Sleep Restriction in Dam Rats. Indian Journal of Medical Research, 136, 1025-1030. 
Submit or recommend next manuscript to SCIRP and we will provide best service for you:

Accepting pre-submission inquiries through Email, Facebook, LinkedIn, Twitter, etc. A wide selection of journals (inclusive of 9 subjects, more than 200 journals)

Providing 24-hour high-quality service

User-friendly online submission system

Fair and swift peer-review system

Efficient typesetting and proofreading procedure

Display of the result of downloads and visits, as well as the number of cited articles Maximum dissemination of your research work

Submit your manuscript at: http://papersubmission.scirp.org/

Or contact jdm@scirp.org 